\title{
Pro-adrenomedullin, pro-endothelin-1, procalcitonin, C-reactive protein and mortality risk in critically ill children: a prospective study
}

\author{
Corsino Rey ${ }^{1 *}$, Irene García-Hernández², Andrés Concha, Pablo Martínez-Camblor ${ }^{3}$, Marta Botrán",
} Alberto Medina', Belén Prieto ${ }^{5}$ and Jesús López-Herce ${ }^{4}$

\begin{abstract}
Introduction: We tested the hypothesis that higher mid-regional pro-adrenomedullin (MR-proADM), carboxy-terminal pro-endothelin-1 (CT-proET-1), procalcitonin (PCT) and C-reactive protein (CRP) plasma concentrations would be associated with increased prediction of mortality risk scores.

Methods: Prospective observational study set in two pediatric intensive care units (PICUs). Two-hundred-thirty-eight patients were included. MR-proADM, CT-proET-1, PCT and CRP levels were compared between children with PRISM III and PIM $2>$ p75 (Group A; $n=33$ ) and the rest (Group B; $n=205$ ).

Results: Median (range) MR-proADM levels were $1.39 \mathrm{nmol} / \mathrm{L}(0.52-12.67)$ in group A versus 0.54 (0.15-3.85) in group $B$ $(P<0.001)$. CT-proET-1 levels were $172 \mathrm{pmol} / \mathrm{L}$ (27-500) versus 58 (4-447) $(P<0.001)$. PCT levels were $7.77 \mathrm{ng} / \mathrm{mL}$ $(0.34-552.00)$ versus $0.28(0.02-107.00)(P<0.001)$. CRP levels were $6.23 \mathrm{mg} / \mathrm{dL}(0.08-28.25)$ versus $1.30 \mathrm{mg} / \mathrm{dL}(0.00-42.09)$ $(P=0.210)$. The area under the ROC curve (AUC) for the differentiation of group A and B was 0.87 (95\% Cl:0.81-0.821) for MR-proADM, 0.86 (95\% Cl:0.79-0.92) for CT-proET-1 and 0.84 (95\% Cl:0.74-0.94) for PCT. A MR-proADM > 0.79 nmol/L had 93\% sensitivity and 76\% specificity to differentiate groups, whereas a CT-proET-1 > 123 pmol/L had 77\% sensitivity and $84 \%$ specificity, and a PCT concentration $>2.05 \mathrm{ng} / \mathrm{mL}$ had $80 \%$ sensitivity and specificity.

Conclusions: In critically ill children, high levels of MR-proADM, CT-proET-1 and PCT were associated with increased prediction of mortality risk scores. MR-proADM, CT-proET-1 and PCT concentrations higher than $0.80 \mathrm{nmol} / \mathrm{L}$, $123 \mathrm{pmol} / \mathrm{L}$ and $2 \mathrm{ng} / \mathrm{mL}$, respectively, could be used by clinicians to identify critically ill children at higher prediction of risk death scores.
\end{abstract}

\section{Introduction}

Having available tools to determine the prognosis of critically ill children at admission to the Pediatric Intensive Care Unit (PICU), or during the first 24 hours after admission, constitutes a clinical necessity. The better evaluated tools have been scales developed to estimate the mortality risk depending on clinical signs and routine analysis. The most used scales are Pediatric Risk of Mortality (PRISM III) and Pediatric Index of Mortality (PIM 2) [1-5].

Procalcitonin (PCT) was initially used to determine sepsis diagnosis [6] and, afterwards, to help in severity classification of patients [7] and to guide antibiotic

\footnotetext{
* Correspondence: corsino.rey@sespa.princast.es

'UCI Pediátrica, Departamento de Pediatría, Hospital Universitario Central de Asturias, Celestino Villamil s/n, Oviedo 33006, Spain

Full list of author information is available at the end of the article
}

treatment duration [8]. C-reactive protein (CRP) rises in response to infectious and inflammatory diseases and shows greater elevations in serious bacterial $[6,7,9,10]$ infections. CRP has been shown to be elevated in adult patients with a higher mortality risk [11,12].

Recently, new readily measurable circulating biomarkers have been described as an additional tool for severity classification of septic patients and prediction of mortality in critically ill patients. Adrenomedullin $(\mathrm{ADM})$ and endothelin-1 (ET-1) are included among these new biomarkers [13-21]. ADM is mainly released from endothelial cells, acts as a potent vasodilator and has natriuretic effects [22,23]. Other ADM properties include a reduction in endothelial permeability [24], bactericidal

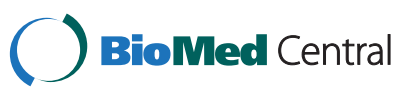

(C) 2013 Rey et al.; licensee BioMed Central Ltd. This is an open access article distributed under the terms of the Creative Commons Attribution License (http://creativecommons.org/licenses/by/2.0), which permits unrestricted use, distribution, and reproduction in any medium, provided the original work is properly cited. 
effects and down-regulation of pro-inflammatory cytokines [25]. ET-1 is a potent vasoconstrictor agent, synthesized mainly by endothelial cells. Elevated levels of ET-1 were found during systemic infections [16] and ET-1 levels correlated with mortality risk [21]. Recently, assays have become available to determine circulating mid-regional pro-adrenomedullin (MR-proADM) and carboxy-terminal pro-endothelin-1 (CT-proET-1) concentrations [26,27]. These peptides are co-synthesized with ADM and ET-1, respectively, and have the advantage of a longer half-life, lack of bioactivity and lack of protein binding, which makes them more suitable for daily practice [28]. Briefly, on admission, concentrations of MR-proADM and CTproET-1 were shown to increase gradually in correlation with severity ranging from systemic inflammatory response syndrome (SIRS) to severe forms of sepsis or with the pneumonia severity index (PSI) [13,14,21].

So far, no data are available for pediatric patients. Therefore, the objective of our study was the investigation of MR-proADM, CT-proET-1, PCT and CRP levels in a well-defined cohort of consecutive PICU patients to test the hypothesis that higher plasma concentrations would be associated with increased prediction of mortality risk scores in critically ill children. As a secondary objective, we also tested the hypothesis that higher plasma marker concentrations would be associated with a number of organ failures $>1$.

\section{Materials and methods}

We designed a prospective observational study set in two PICUs of University Hospitals (eight-bed PICU of Hospital Universitario Central de Asturias in Oviedo and eleven-bed PICU of Hospital Universitario Gregorio Marañón in Madrid). The study protocol was approved by the Hospital Ethics Committee of Hospital Universitario Central de Asturias. Written informed consent was obtained from the patients' parents or guardians and from children above 12 years old.

The study was conducted in 254 consecutive patients, age $<18$ years, who were admitted to one of these PICUs. The exclusion criteria were no blood extraction during the first 12 hours and parents, guardians or children above 12 years old who did not consent to participate. A total of 56 patients were excluded for these reasons. The following variables were prospectively recorded at admission: age, weight, cause of PICU admission, diagnosis and previous diseases. Respiratory rate (RR), heart rate (HR), blood pressure (BP), $\mathrm{O}_{2}$ saturation $\left(\right.$ Sat $\left.\mathrm{O}_{2}\right)$, urine rate and administration of vasopressor agents were recorded hourly. Radiographic and microbiologic diagnostics were performed when indicated. Blood cultures were performed when there was clinical suspicion of infection or if a patient's temperature was $>38^{\circ}$. The PIM 2 value was calculated at admission and PRISM III during the first 12 hours after admission, as it was the normal clinical practice. PIM 2 and PRISM III had been previously validated in both PICUs [1]. Biochemical routine determinations including CRP and PCT were performed during the first 12 hours after admission. Venous blood samples were collected in tubes containing ethylenediaminetetraacetic acid (EDTA). A plasma aliquot was frozen and stored at $-80^{\circ} \mathrm{C}$ for further determination of MRproADM and CT-proET-1.

\section{Mortality risk groups}

Patients were divided into two groups according to mortality risk scores. The higher score risk mortality group (Group A) included patients with a PIM 2 and PRISM III score $>$ p75 $(n=33)$; the lower score risk mortality group (Group B) included patients with a PIM 2 and/or PRISM score $\leq \mathrm{p} 75(\mathrm{n}=221)$.

\section{Number of organ failures groups}

Patients were divided into two groups according to the number of organ failures (cardiovascular, respiratory, neurological, hematological, renal and hepatic) following conference consensus criteria [29]. Group A1 included patients with a number of organ failures $>1(n=71)$ whereas group B1 included patients with $<2$ organ failures $(n=182)$.

\section{Infectious subgroups}

Patients were classified as infectious or non-infectious subgroups during the first 24 hours after admission according to the definitions of the European Society of Intensive Care/Society of Critical Care Medicine [30] modified for use in pediatrics [29].

\section{Measurement of CRP, PCT, MR-pro-adrenomedullin and CT-proET-1}

MR-proADM, CT-proET-1 and PCT were measured in EDTA plasma using a sandwich immunoassay (TRACE technology; Brahms, Hennigsdorf, Germany). Analytical detection limits were $0.08 \mathrm{nmol} / \mathrm{L}$ for pro-ADM, 0.4 $\mathrm{pmol} / \mathrm{L}$ for CT-proET-1 and $0.02 \mathrm{ng} / \mathrm{mL}$ for PCT. Plasma CRP was measured on a Modular Analytics Cobacs 6000 (Roche diagnostics, Indianapolis, IN, USA) by an immunoturbidimetric technique. Analytical detection limit was $0.07 \mathrm{mg} / \mathrm{dL}$.

\section{Statistical analysis}

Patients' clinical and biological parameters were described using frequencies, percentages, medians and ranges. The two groups of patients (A versus B; A1 versus B1) were compared using the non-parametric Mann-Whitney $U$ test for continuous variables and the exact $\chi^{2}$ test for categorical data. Receiver operating characteristic (ROC) curves and the respective areas under the curve (AUC) 
were calculated; for these parameters $95 \%$ confidence intervals were also reported. The AUCs were compared in order to establish the marker with the highest global diagnostic efficiency to calculate mortality risk scores and number of organ failures. The Youden criterion was used to establish threshold (cut-off) values and to build decision rules to differentiate groups A versus B and A1 versus B1. In addition, in order to measure the quality of these decision rules, a leave-one-out method was developed and the obtained sensitivity, specificity, positive predictive (PPV) and negative predictive (NPV) values are reported. Trying to find a combined score of biomarkers model, a multivariate logistic regression analysis which included a stepwise method based on the likelihood ratio has been explored. A $P$-value $<0.05$ was considered statistically significant.

\section{Results}

Baseline characteristics

Two hundred fifty four patients were included in the study (150 boys and 104 girls).

Baseline demographic, clinical and laboratory characteristics of the patients are shown in Table 1. More than half were younger than four years old. The main reasons for PICU admission were postoperative, cardiac surgery, and respiratory and infectious disease. A total of five patients (2\%) died during the PICU hospitalization. Patients with higher risk of mortality scores (group A) were younger than group $B$ patients.

PCT, MR-proADM and CT-proET-1 plasma levels were significantly higher in patients with higher risk of mortality scores (group A) (Table 1). CRP plasma level

Table 1 Demographic, clinical, laboratory and markers data

\begin{tabular}{|c|c|c|c|c|}
\hline Demographic and clinical characteristics & Group A $(n=33)$ & Group B $(n=221)$ & $P$-value & Overall population $\mathrm{N}=254$ \\
\hline Age at admission (months) & $19(50)$ & $45(99)$ & 0.012 & $44(81)$ \\
\hline Weight (kg) & $11.0(10.5)$ & $16.0(22.0)$ & 0.005 & $15.0(17.4)$ \\
\hline Male sex (\%) & 60,6 & 58,8 & 0,853 & 59,1 \\
\hline Admission diagnosis & Group A $(n=33)$ & Group B $(n=221)$ & $P$-value & Overall population $\mathrm{N}=254$ \\
\hline Postoperative & $1(1.7)$ & $59(98.7)$ & $<0.001$ & $60(23.6)$ \\
\hline Cardiac surgery & $21(44.7)$ & $26(55.3)$ & 0.560 & $47(18.5)$ \\
\hline Respiratory & $1(2.2)$ & $44(97.8)$ & $<0.001$ & $45(17.7)$ \\
\hline Infectious & $5(12.5)$ & $35(87.5)$ & $<0.001$ & $40(15.7)$ \\
\hline Traumatic & $2(11.8)$ & $15(88.2)$ & 0.002 & $17(6.7)$ \\
\hline Neurologic & $10(100)$ & $0(0)$ & - & $10(3.9)$ \\
\hline Metabolic-Renal & $1(11.1)$ & $8(88.9)$ & 0.039 & $9(3.6)$ \\
\hline Others & $2(7.7)$ & $24(92.3)$ & $<0.001$ & $26(16.8)$ \\
\hline PRISM III (absolute value) & $13.0(7.5)$ & $2.0(5.0)$ & $<0.001$ & $3.0(8.0)$ \\
\hline PIM 2 (\%) & $4.2(6.7)$ & $0.8(1.0)$ & $<0.001$ & $0.9(1.73)$ \\
\hline Laboratory data & Group A $(n=33)$ & Group B $(n=221)$ & $P$-value & Overall population $\mathrm{N}=254$ \\
\hline$\overline{\mathrm{pH}}$ & $7.26(0.16)$ & $7.35(0.10)$ & 0.001 & $7.34(0.10)$ \\
\hline Bicarbonate (mEq/L) & $16.8(8.9)$ & $21.9(3.9)$ & 0.030 & $21.8(3.9)$ \\
\hline Lactate $(\mathrm{mmol} / \mathrm{L})$ & $1.20(1.13)$ & $0.90(1.10)$ & 0.027 & $1.00(1.10)$ \\
\hline Platelets (X1000/mm3) & $228.5(240.4)$ & $289.0(169.0)$ & 0.043 & $281.0(168.0)$ \\
\hline Markers & Group A $(n=33)$ & Group B $(n=221)$ & $P$-value & Overall population $\mathrm{N}=254$ \\
\hline $\mathrm{CRP}(\mathrm{mg} / \mathrm{dl})$ & $6.23(15.5)$ & $1.30(8.8)$ & 0.210 & $1.47(10.1)$ \\
\hline PCT (ng/ml) & $7.76(25.81)$ & $0.27(1.36)$ & $<0.001$ & $0.34(1.83)$ \\
\hline MR-proADM (nmol/l) & $1.39(1.59)$ & $0.53(0.41)$ & $<0.001$ & $0.58(0.39)$ \\
\hline CT-proET-1 (pmol/l) & $172.3(82.70)$ & $58.47(56.50)$ & $<0.001$ & $67.59(53.13)$ \\
\hline Markers & Group A1 $(n=71)$ & Group B1 $(n=182)$ & $P$-value & Overall population $\mathrm{N}=\mathbf{2 5 3}$ \\
\hline $\mathrm{CRP}(\mathrm{mg} / \mathrm{dl})$ & $9.57(15.4)$ & $1.07(7.5)$ & $<0.001$ & $1.47(10.1)$ \\
\hline PCT (ng/ml) & $4.91(32.7)$ & $0.20(1.28)$ & $<0.001$ & $0.34(1.83)$ \\
\hline MR-proADM (nmol/l) & $1.380(1.60)$ & $0.471(0.28)$ & $<0.001$ & $0.58(0.39)$ \\
\hline CT-proET-1 (pmol/l) & $159.09(97.40)$ & $52.65(41.00)$ & $<0.001$ & $67.59(53.13)$ \\
\hline
\end{tabular}

Group A: Higher score risk mortality group. Group B: Lower score risk mortality group; Group A1: number of organ failures >1. Group A2: number of organ failures <2; admission diagnosis is described by the absolute and relative values (\%); the rest of the variables are described by median and interquartile range. CRP: C-reactive protein; CT-pro-ET1: C-terminal-pro-endothelin-1; PCT:procalcitonin; MR-pro-ADM: midregional-pro-adrenomedullin. 
was not different between both groups. CRP, PCT, MRproADM and CT-proET-1 plasma levels were significantly higher in patients with two or more number of organ failures (group A1) (Table 1).

\section{Value for CRP, PCT, MR-proADM and CT-proET-1 in prediction of risk of mortality scores}

To evaluate the value for CRP, PCT, MR-proADM and CT-proET-1 in the prediction of risk of mortality scores, ROC curve analysis was performed for each prohormone (Table 2 and Figure 1). The optimal cut-off value of PCT for predicting risk of mortality scores was $2.05 \mathrm{ng} / \mathrm{ml}$, showing a similar sensitivity and specificity of $80 \%$. A MR-proADM concentration higher than $0.79 \mathrm{nmol} / \mathrm{L}$ had $93 \%$ sensitivity and $76 \%$ specificity, whereas a CT-proET-1 concentration higher than 123 $\mathrm{pmol} / \mathrm{L}$ had $77 \%$ sensitivity and $84 \%$ specificity.

\section{Value for CRP, PCT, MR-ProADM and CT-pro-ET1 in} prediction of number of organ failures

ROC curve analysis was performed for each biomarker (Table 2 and Figure 2). A CRP level of $3.76 \mathrm{mg} / \mathrm{dL}$ showed a sensitivity of $75 \%$ and a specificity of $65 \%$; a PCT level of $4.12 \mathrm{ng} / \mathrm{mL}$ gave a sensitivity of $61 \%$ and a specificity of $88 \%$; a MR-proADM concentration higher than $0.77 \mathrm{nmol} / \mathrm{L}$ had $91 \%$ sensitivity and $85 \%$ specificity,

Table 2 CRP, PCT, MR-pro-ADM and CT-pro-ET-1 measurements in prediction of risk mortality scores and organ failure

\begin{tabular}{|c|c|c|}
\hline \multirow[t]{2}{*}{ Parameters } & \multicolumn{2}{|c|}{ AUC (95\% interval confidence) } \\
\hline & Risk mortality score & Organ failure $(+1)$ \\
\hline CRP & 0.608 (0.452 to 0.764$)$ & 0.713 (0.609 to 0.816$)$ \\
\hline PCT & 0.839 (0.739 to 0.940$)$ & 0.804 (0.715 to 0.892$)$ \\
\hline Pro-ADM & 0.866 (0.810 to 0.821$)$ & 0.922 (0.887 to 0.957$)$ \\
\hline \multirow[t]{3}{*}{ CT-proET-1 } & 0.853 (0.784 to 0.922 ) & 0.915 (0.876 to 0.954$)$ \\
\hline & \multicolumn{2}{|c|}{ Risk mortality score } \\
\hline & Without infection & With infection \\
\hline CRP & 0.753 (0.534 to 0.971$)$ & $0.468(0.232$ to 0.705$)$ \\
\hline PCT & 0.955 (0.876 to 1.035$)$ & 0.710 (0.499 to 0.922$)$ \\
\hline MR-pro-ADM & 0.886 (0.828 to 0.945$)$ & 0.869 (0.771 to 0.966$)$ \\
\hline \multirow[t]{3}{*}{ CT-proET-1 } & 0.893 (0.839 to 0.948 ) & 0.856 (0.745 to 0.967$)$ \\
\hline & \multicolumn{2}{|c|}{ Organ failure $(+1)$} \\
\hline & Without infection & With infection \\
\hline CRP & 0.770 (0.601 to 0.939$)$ & 0.634 (0.493 to 0.775$)$ \\
\hline PCT & 0.868 (0.738 to 0.977 ) & 0.739 (0.582 to 0.896$)$ \\
\hline MR-pro-ADM & 0.943 (0.906 to 0.980$)$ & 0.901 (0.832 to 0.970$)$ \\
\hline CT-proET-1 & 0.967 (0.942 to 0.993$)$ & 0.804 (0.705 to 0.904$)$ \\
\hline
\end{tabular}

Results are presented for the whole sample and for subgroups of patients with and without infection. ROC curve analysis of CRP (C-reactive protein, $\mathrm{mg} / \mathrm{dl}$ ), $\mathrm{PCT}$ (procalcitonin, ng/ml), MR-pro-ADM (midregional-pro-adrenomedullin, $\mathrm{nmol} / \mathrm{l}$ ) and CT-pro-ET1 (C-terminal-pro-endothelin-1, pmol/l).

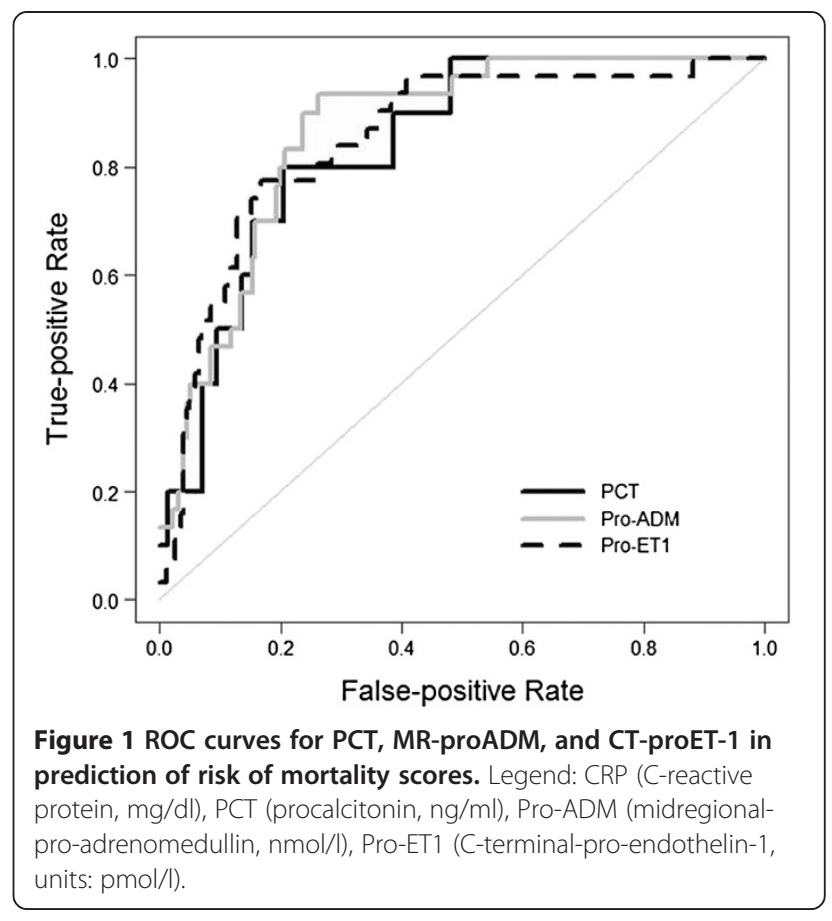

whereas a CT-proET-1 concentration higher than 80 $\mathrm{pmol} / \mathrm{L}$ had $90 \%$ sensitivity and $77 \%$ specificity.

\section{Subgroups analysis}

Patients were classified into infectious or non-infectious subgroups during the first 24 hours after admission. We performed a subgroup analysis of mortality risk scores taking into account this classification (Table 2). In the infectious subgroup a PCT level of $2.05 \mathrm{ng} / \mathrm{mL}$ gave a

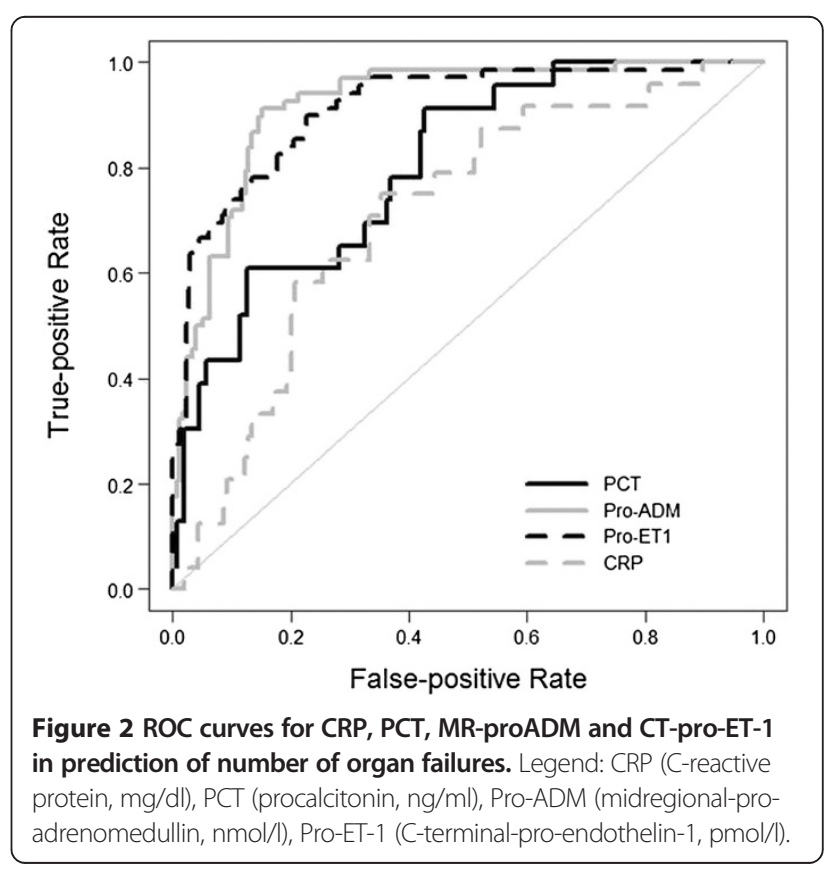


sensitivity of $83 \%$ and a specificity of $58 \%$; a MRproADM concentration higher than $0.80 \mathrm{nmol} / \mathrm{L}$ had $100 \%$ sensitivity and $70 \%$ specificity, whereas a CTproET-1 concentration higher than $80.57 \mathrm{pmol} / \mathrm{L}$ had $75 \%$ sensitivity and $86 \%$ specificity.

In the non-infectious subgroup a PCT level of $0.58 \mathrm{ng} /$ $\mathrm{mL}$ gave a sensitivity of 100 and a specificity of 82 , a MRproADM concentration higher than $0.84 \mathrm{nmol} / \mathrm{L}$ had $91 \%$ sensitivity and $82 \%$ specificity, whereas a CT-proET-1 concentration higher than $83.50 \mathrm{pmol} / \mathrm{L}$ had $91 \%$ sensitivity and $70 \%$ specificity.

We also performed an infectious versus non-infectious subgroup analysis to differentiate the number of organ failures (Table 2). In the infectious subgroup a PCT level of $4.12 \mathrm{ng} / \mathrm{mL}$ gave a sensitivity of $71 \%$ and a specificity of $70 \%$, a MR-proADM concentration higher than $0.81 \mathrm{nmol} /$ L had $84 \%$ sensitivity and $79 \%$ specificity, whereas a CTproET-1 concentration higher than $79.5 \mathrm{pmol} / \mathrm{L}$ had $79 \%$ sensitivity and $66 \%$ specificity.

In the non-infectious subgroup a PCT level of $0.40 \mathrm{ng} /$ $\mathrm{mL}$ gave a sensitivity of $89 \%$ and a specificity of $77 \%$, a MR-proADM concentration higher than $0.77 \mathrm{nmol} / \mathrm{L}$ had $90 \%$ sensitivity and $91 \%$ specificity, whereas a pro-ET1 concentration higher than $87.3 \mathrm{pmol} / \mathrm{L}$ had $93 \%$ sensitivity and $89 \%$ specificity.

\section{Analysis of quality of decision rules: cross-validation results}

We performed a cross validation method to test the quality of decision rules. Results for the obtained sensitivity, specificity, PPV and NPV values are reported in Table 3.

\section{Combined score of biomarkers}

We developed several scores with the best AUCs obtained with the combination of two markers. The AUC for the combination of MR-proADM and PCT in the prediction of PICU risk of mortality scores was 0.935 (0.842 to 0.978) when the decision was based on the score S1 (S1 = $1.39 \cdot$ MR-proADM $+0.01 \cdot$ PCT) which with a threshold of 1.70 leads to a sensitivity of $90.0 \%$ and a specificity of $90.1 \%$ (PPV and NPV were 34.6 and 99.3, respectively). The AUC for the combination of MR-proADM and CT-pro-ET1 was 0.900 (0.858 to 0.942$)$ for decision based on the score S2 $(\mathrm{S} 2=0.77 \cdot \mathrm{MR}$-proADM $+0.01 \cdot \mathrm{CT}$-pro-ET1) which with a cut-off value of 1.85 obtained a sensitivity of $90 \%$ and a specificity of $80.3 \%$ (PPV was $38.6 \%$ and NPV 98.3\%). The AUC for the combination of MR-proADM and PCT in the prediction of more than 1 organ failure was 0.904 (0.848 to 0.981$)$ when the decision was based on the score S3 (S3 $=2.04 \cdot \mathrm{MR}$-proADM + 0.02 $\cdot \mathrm{PCT})$ which with a threshold of 2.00 achieved a sensitivity and a specificity of $82.6 \%$ and $89.2 \%$, respectively (PPV of $52.8 \%$ and NPV of 97.2\%). The AUC for the combination of MR-proADM and CT-pro-ET1 was 0.945 (0.918 to 0.973) for the score
Table 3 Sensitivity, specificity, positive predictive values and negative predictive values of CPR, PCT, MR-proADM and CT-pro-ET1

\begin{tabular}{|c|c|c|c|c|c|c|c|c|}
\hline \multirow[b]{2}{*}{ Parameters } & \multicolumn{4}{|c|}{ PICU risk mortality score } & \multicolumn{4}{|c|}{ Organ failure $(+1)$} \\
\hline & $\mathrm{Se}$ & Sp & PPV & NPV & $\mathrm{Se}$ & Sp & PPV & NPV \\
\hline CRP & 0.416 & 0 & 2 & +2 & 83 & 0.642 & 92 & 0.914 \\
\hline CT & 00 & 0.798 & 0.167 & 0.979 & 610 & 0.569 & 0.169 & 0.910 \\
\hline MR-ProADM & 00 & 0 & 0 & 2 & 97 & 0.850 & 0.693 & 0.956 \\
\hline \multirow[t]{3}{*}{ T-proET-1 } & 10 & +1 & 0.386 & 0.954 & 0.884 & 0.768 & .592 & .946 \\
\hline & \multicolumn{8}{|c|}{ PICU risk mortality score } \\
\hline & \multicolumn{4}{|c|}{ Without infection } & \multicolumn{4}{|c|}{ With infection } \\
\hline s & Se & Sp & PPV & NPV & Se & Sp & PPV & NPV \\
\hline CRP & 0.400 & 0.865 & 0.125 & 0.968 & 0.500 & 0.365 & 0.060 & 0.900 \\
\hline$T$ & 0 & 0.8 & 0 & 38 & 00 & 0.573 & 0.088 & 0 \\
\hline 1R-pr & 0.863 & 0.817 & 0.422 & 0.974 & 0.875 & 0.701 & 0.233 & 0.982 \\
\hline \multirow[t]{3}{*}{ CT-proET-1 } & 0.773 & 0.866 & 0.472 & 0.960 & 0.625 & 0.833 & 0.278 & 0.956 \\
\hline & \multicolumn{8}{|c|}{ Organ failure $(+1)$} \\
\hline & \multicolumn{4}{|c|}{ Without infection } & \multicolumn{4}{|c|}{ With infection } \\
\hline Parar & Se & Sp & PPV & NPV & Se & Sp & PPV & NPV \\
\hline RPP & 0.778 & 0.677 & 0.179 & 0.971 & 0.643 & 0.606 & 0.257 & 0.889 \\
\hline$C T$ & 0.778 & 0.758 & 0.233 & 0.973 & 0.428 & 0.938 & 0.600 & 0884 \\
\hline MR-proADM & 0.898 & 0.877 & 0.759 & 0.952 & 0.895 & 0.742 & 0.500 & 0.961 \\
\hline T-proET-1 & 0.918 & 0.894 & 0.789 & 0.962 & 0.842 & 0.492 & 0.320 & 0.917 \\
\hline
\end{tabular}

Legend: Results obtained after applying a cross validation method to test the quality of decision rules, presented for the whole sample and for subgroups of patients with and without infection. CRP (C-reactive protein, $\mathrm{mg} / \mathrm{dl}$ ), PCT (procalcitonin, $\mathrm{ng} / \mathrm{ml}$ ), MR-pro-ADM (midregional-pro-adrenomedullin, $\mathrm{nmol} / \mathrm{l}$ ), CT-pro-ET-1 (C-terminal-pro-endothelin-1, pmol/I). Se: sensitivity. Sp: specificity. NPV: negative predictive value. PPV: positive predictive value.

S4 $(\mathrm{S} 4=1.53 \cdot$ MR-proADM + 0.03 $\cdot$ CT-pro-ET1); a cut-off value of 3.65 yielded a sensitivity of $97.1 \%$ and a specificity of $79.9 \%$ (PPV and NPV were $64.7 \%$ and $98.6 \%$, respectively). The combination of MR-proADM and CRP did not improve MR-proADM accuracy.

\section{Discussion}

An important issue in pediatric critical care is the improvement of prognostic assessment. Markers that are able to stratify critically ill children depending on the risk of mortality could help physicians to make decisions. To our knowledge, this is the first prospective study in critically ill children which tries to identify vasoactive biomarkers as outcome predictors. We have shown that high levels of MR-proADM, CT-proET-1 and PCT are associated with increased risk of mortality scores as well as increased risk of number of organ failures in a heterogeneous sample of critically ill children. We cannot use mortality as the gold standard to differentiate a patient's prognosis because PICU mortality was low in our sample. Therefore, we used other surrogate markers of PICU outcome, such as mortality scores. Numbers of organ failures are other criteria of severity 
in critically ill children. In our sample, more than $90 \%$ of the patients with a higher risk of mortality had two or more number of organ failures.

\section{Mortality risk}

Children with higher risk of mortality scores were younger, and presented at admission with lower $\mathrm{pH}$, bicarbonate and platelets, and higher lactate (Table 1). Previous studies have shown a higher risk of mortality in younger children [1,31]. Lactate levels correlated with mortality in postoperative cardiac surgery children $[32,33]$ as well as critically ill adult patients [34]. A low level of platelets correlated with mortality increase [35].

The main objective of our study was to identify biomarkers as risk mortality predictors. CRP has been shown to be elevated in adult patients with higher mortality risk $[11,12]$. In agreement with other studies $[9,10]$, we found no significant differences in CRP concentrations between group A and B patients. Slow CRP kinetics could explain this finding. PCT levels increased in direct relation to disease severity [7,36-38]. We found that a PCT cut-off value of $2.05 \mathrm{ng} / \mathrm{mL}$ predicted risk of mortality scores with $80 \%$ sensitivity and specificity. When analyzing subgroups of patients, we found that PCT was a better marker of mortality risk scores in the non-infectious subgroup (Table 2). Cut-off level decreases to $0.58 \mathrm{ng} / \mathrm{mL}$ with higher sensitivity and specificity. To explain this decrease in cut-off level and better performance we have to take into account that in patients with bacterial infection PCT increase is due to both infection and disease severity, whereas in patients without infection the only reason for a PCT increase is the acute inflammatory process from a high severity shock, trauma and so on. Therefore, when bacterial infection is absent a PCT increase could be directly related to disease severity.

To date, few data are available regarding the potential of vasoactive pro-hormones as biomarkers in mortality risk determination. MR-proADM was evaluated as a severity marker in septic adult patients with promising results [39]. Increased admission levels of MR-proADM in critically ill patients have been associated with increased mortality $[39,40]$. We found that MR-proADM can be useful to identify critically ill children with different risk of mortality scores. Areas under the ROC curve range from 0.67 in the study of Schuetz et al. [15] to 0.87 in the Wang et al. study [40] with an intermediate value of 0.81 in the study of Christ-Crain et al. [18] in patients with sepsis and septic shock. We obtained a value of 0.86. Our MR-proADM cut-off value of $0.79 \mathrm{nmol} / \mathrm{L}$ was similar to values of 0.95 described to predict mortality in community-acquired pneumonia patients [41] but lower than the value of $3.9 \mathrm{nmol} / \mathrm{L}$ obtained by ChristCrain et al. [18] in septic patients. The reason could be different patients and different methodology. In our patients, we tried to differentiate risk of mortality scores at the level of p75 whereas Christ-Crain et al. [18] tried to differentiate survival versus nonsurvival patients. We only found a pediatric study in septic neonates comparing MR-proADM levels between survivors and nonsurvivors. MR-proADM levels were $5.22 \mathrm{nmol} / \mathrm{L}$ and $11.40 \mathrm{nmol} / \mathrm{L}$, respectively [42]. However, these values had to be analyzed with caution due to other factors that can increase MRproADM in neonatal patients.

CT-proET-1 was also a good marker of mortality risk with AUCs under the ROC curve similar to MRproADM. Brauner et al. [21] also found an association between CT-proET-1 levels and mortality in septic shock patients. Other adult studies did not find differences in CT-proET-1 levels between survivors and non-survivors $[15,43]$.

Different from PCT, MR-proADM and CT-proET-1 areas under ROC curve were similar in patients with and without infection. Moreover, PCT cut-off levels were different in infectious versus non-infectious patients, whereas MR-proADM and CT-proET-1 cut-off levels were almost the same in both groups of patients. This is an advantage for both vasoactive peptides that were not influenced by the infectious situation of the patient.

\section{Number of organ failures}

The performance of biomarkers to identify patients with two or more organ failures was similar to that previously described for risk of mortality, except for CRP. We found higher serum CRP levels in children from group A1 versus B1. Lobo et al. [11] showed a higher incidence of respiratory, renal and hematologic organ failures in patients with CRP levels higher than $10 \mathrm{ng} / \mathrm{mL}$. Our cutoff value to differentiate groups A1 and B1 was $3.76 \mathrm{mg} / \mathrm{dl}$. Values for the areas under the ROC curve to differentiate group A1 versus B1 were acceptable for CRP, good for PCT and excellent for CT-proET-1 and MR-proADM (Table 2 and Figure 2). PCT cut-off values of $4.12 \mathrm{ng} / \mathrm{mL}$ were higher than previous values for mortality risk whereas MR-proADM cut-off values of $0.77 \mathrm{nmol} / \mathrm{L}$ were similar and CT-proET-1 cut-off values of $80.57 \mathrm{pmol} / \mathrm{L}$ were lower. Several studies found a correlation between PCT increase during the first 24 hours after admission [44] or postoperative PCT increase [45] and number of organ failures. Ueda et al. [46] showed a correlation between MRproADM levels and the multiple organ failure score.

\section{Analysis of quality of decision rules: cross-validation results}

As expected, the values of sensitivity, specificity, NPV and especially PPV were lower after performing a crossvalidation test. However, the information given by the markers, especially MR-proADM, appears to improve 
diagnostic accuracy for detection of patients with higher risk of mortality scores and more than one organ failure.

\section{Combined score of biomarkers}

The single marker with the greatest AUC was MRproADM. Combination of MR-proADM with each of the other markers slightly improves diagnostic efficiency to differentiate groups. We have developed several scores with the best AUCs obtained with the combinations of MRproADM and PCT, and MR-proADM and CT-proET1.

\section{Prognostic assessment}

The additional value of information provided by biomarkers when compared with scoring systems has to be further evaluated in order to translate their measurements into clinical practice. PRISM III and PIM 2 scores have been validated for mortality risk stratification, but tend to be used more for audit and research than clinical decision making [1,3-5]. A rapidly available biochemical test that provides similar prognostic information could, therefore, be useful, for example, to help discussions about prognosis with patients' relatives and decisions regarding earlier interventions. Future work should clarify whether the increase of MR-proADM and CT-proET-1 in pediatric patients with higher risk of mortality results from an upregulation of biomarker secretion in patients with different organ failures. A rising PCT level is currently used as an indicator that an infectious process is not under control and that better source control is required [47]. Future work should clarify whether PCT at a low cut-off level could be used for prognosis in non-infectious patients.

Our study has limitations. First, taking into account that it was not sufficiently powered to pick up differences in survival, we used other surrogate markers of PICU outcome, such as mortality scores, against which the biomarkers diagnostic criteria can be calibrated. Second, we have performed an observational study that does not allow drawing any conclusion concerning therapeutic interventions. Third, this was a two-center study that includes different groups of critically ill children. The value for biomarkers in prediction of adverse outcome would be different if the population was different. Fourth, biomarker levels were analyzed during the first 12 hours after PICU admission, but follow-up measurements were not available. Evolution of biomarker levels during the first admission days would have higher accuracy. However, an early mortality prediction is more useful in clinical practice. Fifth, the A and B groups were different in terms of diagnosis. We cannot totally rule out that this difference has influenced biomarkers levels.

\section{Conclusions}

High levels of MR-proADM, CT-proET-1 and PCT were associated with increased prediction of mortality risk scores. MR-proADM, CT-proET-1 and PCT concentrations higher than $0.80 \mathrm{nmol} / \mathrm{L}, 123 \mathrm{pmol} / \mathrm{L}$ and $2 \mathrm{ng} / \mathrm{mL}$, respectively, could be used by clinicians to identify critically ill children at higher prediction of death risk score.

\section{Key messages}

- MR-proADM, CT-proET-1 and PCT levels during the first 12 hours after PICU admission are associated with increased prediction of mortality risk score in critically ill children.

- The cut-off level to identify critically ill children at higher score risk of death were $0.80 \mathrm{nmol} / \mathrm{L}$ for MR-proADM, $123 \mathrm{pmol} / \mathrm{L}$ for CT-proET-1 and 2 $\mathrm{ng} / \mathrm{mL}$ for PCT.

- The additional value of these combinations of biomarker cut-off levels when compared with scoring systems has to be further evaluated in order to translate their measurement into clinical practice.

\section{Abbreviations}

ADM: adrenomedullin; AUC: area under curve; CRP: C-reactive protein; CT-pro-ET-1: C-terminal-pro-endothelin-1; ET-1: endothelin-1; MR-proADM: midregional-pro-adrenomedullin; p75: 75 percentile; PCT: procalcitonin; PICU: pediatric intensive care unit; PIM 2: Pediatric Index of Mortality 2; PRISM III: Pediatric Risk of Mortality III; ROC: Receiver Operating Characteristic; SIRS: systemic inflammatory response syndrome.

\section{Competing interests}

Corsino Rey has received speaker honoraria from Brahms and Thermofisher Companies to attend meetings related to sepsis biomarkers. The other authors declare that they have no conflicts of interest.

\section{Authors' contributions}

CR participated in protocol conception and design, obtaining funding, subject enrollment (PICU patients), data collection, interpretation of data and wrote the first draft of the manuscript. IG-H participated in subject enrollment, data collection and interpretation of data. AC participated in subject enrollment, data collection and drafting the manuscript. PM-C participated in study design, statistical data analysis and interpretation. MB participated in subject enrollment of Hospital Universitario Gregorio Marañón patients, data collection and drafting the manuscript. AM participated in subject enrollment, data collection and drafting the manuscript. BP participated in laboratory sample management and interpretation of data. JL-H participated in protocol conception and design, interpretation of data and drafting the manuscript. All authors read and approved the final manuscript.

\section{Acknowledgements}

The authors gratefully acknowledge the assistance of the PICU medical and nursing staff of Hospital Universitario Central de Asturias and Hospital Universitario Gregorio Marañón. Supported in part by a grant of Foundation 'Ernesto Sánchez Villares'. Kits for determination of MR-proADM and MR-proET1 were provided by Brahms (Hennigsdorf, Germany). The fourth author (PM-C) was supported by research Grant MTM2011-23204 of the Spanish Ministerio de Ciencia e Innovación. Fundación Ernesto Sánchez Villares, Brahms and Thermofisher Companies, and the Spanish Ministerio de Ciencia e Innovación did not participate in the development of the manuscript, including study design, collection, analysis, interpretation of data, writing of the report and the decision to submit the paper for publication.

\section{Author details}

'UCl Pediátrica, Departamento de Pediatría, Hospital Universitario Central de Asturias, Celestino Villamil s/n, Oviedo 33006, Spain. ${ }^{2}$ Pediatric Service, Complejo Hospitalario Universitario de A Coruña, A Coruña, Spain. ${ }^{3}$ Oficina 
de Investigación Biosanitaria FICYT, University of Oviedo, Oviedo, Spain. ${ }^{4}$ Pediatric Intensive Care Department, Hospital General Universitario Gregorio Marañón, Instituto de Investigación Sanitaria Gregorio Marañón, Madrid Spain. ${ }^{5}$ Biochemical Department, Hospital Universitario Central de Asturias, University of Oviedo, Oviedo, Spain.

Received: 28 March 2013 Accepted: 17 September 2013

Published: 16 October 2013

\section{References}

1. Prieto ES, Lopez-Herce CJ, Rey GC, Medina VA, Concha TA, Martinez CP: Prognostic indexes of mortality in pediatric intensive care units An Pediatr (Barc) 2007, 66:345-350.

2. Marcin JP, Pollack MM: Review of the methodologies and applications of scoring systems in neonatal and pediatric intensive care. Pediatr Crit Care Med 2000, 1:20-27.

3. Pollack MM, Patel KM, Ruttimann UE: PRISM III: an updated pediatric risk of mortality score. Crit Care Med 1996, 24:743-752

4. Shann F, Pearson G, Slater A, Wilkinson K: Paediatric index of mortality (PIM): a mortality prediction model for children in intensive care. Intensive Care Med 1997, 23:201-207.

5. Slater A, Shann F, Pearson G: PIM2: a revised version of the paediatric index of mortality. Intensive Care Med 2003, 29:278-285.

6. Enguix A, Rey C, Concha A, Medina A, Coto D, Dieguez MA: Comparison of procalcitonin with $C$-reactive protein and serum amyloid for the early diagnosis of bacterial sepsis in critically ill neonates and children. Intensive Care Med 2001, 27:211-215.

7. Rey C, Los AM, Concha A, Medina A, Prieto S, Martinez P, Prieto B: Procalcitonin and $C$-reactive protein as markers of systemic inflammatory response syndrome severity in critically ill children. Intensive Care Med 2007, 33:477-484.

8. Kopterides P, Siempos II, Tsangaris I, Tsantes A, Armaganidis A: Procalcitonin-guided algorithms of antibiotic therapy in the intensive care unit: a systematic review and meta-analysis of randomized controlled trials. Crit Care Med 2010, 38:2229-2241.

9. Claeys R, Vinken S, Spapen H, ver Elst K, Decochez K, Huyghens L, Gorus FK: Plasma procalcitonin and C-reactive protein in acute septic shock: clinical and biological correlates. Crit Care Med 2002, 30:757-762

10. Pettila V, Pentti J, Pettila M, Takkunen O, Jousela I: Predictive value of antithrombin III and serum C-reactive protein concentration in critically ill patients with suspected sepsis. Crit Care Med 2002, 30:271-275.

11. Lobo SM, Lobo FR, Bota DP, Lopes-Ferreira F, Soliman HM, Melot C, Vincent $J \mathrm{~L}$ : C-reactive protein levels correlate with mortality and organ failure in critically ill patients. Chest 2003, 123:2043-2049.

12. Wang F, Pan W, Pan S, Wang S, Ge Q, Ge J: Usefulness of N-terminal probrain natriuretic peptide and C-reactive protein to predict ICU mortality in unselected medical ICU patients: a prospective, observational study. Crit Care 2011, 15:R42.

13. Christ-Crain M, Morgenthaler NG, Stolz D, Muller C, Bingisser R, Harbarth S, Tamm M, Struck J, Bergmann A, Müller B: Pro-adrenomedullin to predict severity and outcome in community-acquired pneumonia [ISRCTN04176397]. Crit Care 2006, 10:R96.

14. Gegenhuber A, Struck J, Dieplinger B, Poelz W, Pacher R, Morgenthaler NG, Bergmann A, Haltmayer M, Mueller T: Comparative evaluation of B-type natriuretic peptide, mid-regional pro-A-type natriuretic peptide, midregional pro-adrenomedullin, and Copeptin to predict 1-year mortality in patients with acute destabilized heart failure. J Card Fail 2007 13:42-49.

15. Schuetz $P$, Christ-Crain M, Morgenthaler NG, Struck J, Bergmann A, Muller B: Circulating precursor levels of endothelin-1 and adrenomedullin, two endothelium-derived, counteracting substances, in sepsis. Endothelium 2007, 14:345-351.

16. Tschaikowsky K, Sagner S, Lehnert N, Kaul M, Ritter J: Endothelin in septic patients: effects on cardiovascular and renal function and its relationship to proinflammatory cytokines. Crit Care Med 2000, 28:1854-1860.

17. Shah R: Endothelins in health and disease. Eur J Intern Med 2007 18:272-282

18. Christ-Crain M, Morgenthaler NG, Struck J, Harbarth S, Bergmann A, Muller B: Mid-regional pro-adrenomedullin as a prognostic marker in sepsis: an observational study. Crit Care 2005, 9:R816-R824.
19. Michels M, Djamiatun K, Faradz SM, Koenders MM, de Mast $Q$, van der Ven AJ: High plasma mid-regional pro-adrenomedullin levels in children with severe dengue virus infections. J Clin Virol 2011, 50:8-12

20. Klip IT, Voors AA, Anker SD, Hillege HL, Struck J, Squire I, van Veldhuisen DJ, Dickstein K, OPTIMAAL investigators: Prognostic value of mid-regional proadrenomedullin in patients with heart failure after an acute myocardial infarction. Heart 2011, 97:892-898.

21. Brauner JS, Rohde LE, Clausell N: Circulating endothelin-1 and tumor necrosis factor-alpha: early predictors of mortality in patients with septic shock. Intensive Care Med 2000, 26:305-313.

22. Kaplan JM, Wong HR: Biomarker discovery and development in pediatric critical care medicine. Pediatr Crit Care Med 2011, 12:165-173.

23. Hinson JP, Kapas S, Smith DM: Adrenomedullin, a multifunctional regulatory peptide. Endocr Rev 2000, 21:138-167.

24. Temmesfeld-Wollbruck B, Hocke AC, Suttorp N, Hippenstiel S: Adrenomedullin and endothelial barrier function. Thromb Haemost 2007 98:944-951.

25. Allaker RP, Grosvenor PW, McAnerney DC, Sheehan BE, Srikanta BH, Pell K, Kapas S: Mechanisms of adrenomedullin antimicrobial action. Peptides 2006, 27:661-666.

26. Morgenthaler NG, Struck J, Alonso C, Bergmann A: Measurement of midregional proadrenomedullin in plasma with an immunoluminometric assay. Clin Chem 2005, 51:1823-1829.

27. Papassotiriou J, Morgenthaler NG, Struck J, Alonso C, Bergmann A: Immunoluminometric assay for measurement of the C-terminal endothelin-1 precursor fragment in human plasma. Clin Chem 2006, 52:1144-1151.

28. Miguel D, Prieto B, Costa M, Coto D, Alvarez FV: Cord blood plasma reference intervals for potential sepsis markers: pro-adrenomedullin, pro-endothelin and pro-atrial natriuretic peptide. Clin Biochem 2011, 44:337-341.

29. Goldstein B, Giroir B, Randolph A: International pediatric sepsis consensus conference: definitions for sepsis and organ dysfunction in pediatrics. Pediatr Crit Care Med 2005, 6:2-8.

30. Levy MM, Fink MP, Marshall JC, Abraham E, Angus D, Cook D, Cohen J, Opal SM, Vincent JL, Ramsay G: SCCM/ESICM/ACCP/ATS/SIS International Sepsis Definitions Conference. Intensive Care Med 2003, 2001:530-538.

31. Eulmesekian $P G$, Perez $A$, Minces $P G$, Ferrero $\mathrm{H}$ : Validation of pediatric index of mortality 2 (PIM2) in a single pediatric intensive care unit of Argentina. Pediatr Crit Care Med 2007, 8:54-57.

32. Basaran M, Sever K, Kafali E, Ugurlucan M, Sayin OA, Tansel T, Alpagut U, Dayioglu E, Onursal E: Serum lactate level has prognostic significance after pediatric cardiac surgery. J Cardiothorac Vasc Anesth 2006, 20:43-47.

33. Rocha TS, Silveira AS, Botta AM, Ricachinevsky CP, Dalle ML, Nogueira A: Serum lactate as mortality and morbidity marker in infants after Jatene's operation. Rev Bras Cir Cardiovasc 2010, 25:350-358.

34. Jansen TC, Van BJ, Woodward R, Mulder PG, Bakker J: Association between blood lactate levels, Sequential Organ Failure Assessment subscores, and 28-day mortality during early and late intensive care unit stay: a retrospective observational study. Crit Care Med 2009, 37:2369-2374.

35. Moreau D, Timsit JF, Vesin A, de Garrouste-Org LA, Zahar JR, Adrie C, Vincent F, Cohen Y, Schlemmer B, Azoulay E: Platelet count decline: an early prognostic marker in critically ill patients with prolonged ICU stays. Chest 2007, 131:1735-1741.

36. Hatherill M, Tibby SM, Turner C, Ratnavel N, Murdoch IA: Procalcitonin and cytokine levels: relationship to organ failure and mortality in pediatric septic shock. Crit Care Med 2000, 28:2591-2594.

37. Jensen JU, Heslet $L$, Jensen $T H$, Espersen $K$, Steffensen $P$, Tvede M: Procalcitonin increase in early identification of critically ill patients at high risk of mortality. Crit Care Med 2006, 34:2596-2602.

38. Han YY, Doughty LA, Kofos D, Sasser H, Carcillo JA: Procalcitonin is persistently increased among children with poor outcome from bacterial sepsis. Pediatr Crit Care Med 2003, 4:21-25.

39. Guignant C, Voirin N, Venet F, Poitevin F, Malcus C, Bohe J, Lepape A, Monneret G: Assessment of pro-vasopressin and pro-adrenomedullin as predictors of 28-day mortality in septic shock patients. Intensive Care Med 2009, 35:1859-1867.

40. Wang RL, Kang FX: Prediction about severity and outcome of sepsis by pro-atrial natriuretic peptide and pro-adrenomedullin. Chin J Traumatol 2010, 13:152-157. 
41. Kruger S, Ewig S, Giersdorf S, Hartmann O, Suttorp N, Welte T: Cardiovascular and inflammatory biomarkers to predict short- and longterm survival in community-acquired pneumonia: results from the German competence network, CAPNETZ. Am J Respir Crit Care Med 2010, 182:1426-1434.

42. Hagag AA, Elmahdy HS, Ezzat AA: Prognostic value of plasma pro-adrenomedullin and antithrombin levels in neonatal sepsis. Indian Pediatr 2011, 48:471-473.

43. Guignant C, Venet F, Voirin N, Poitevin F, Malcus C, Bohe J, Lepape A, Monneret G: Proatrial natriuretic peptide is a better predictor of 28-day mortality in septic shock patients than proendothelin-1. Clin Chem Lab Med 2010, 48:1813-1820.

44. Giamarellos-Bourboulis EJ, Mega A, Grecka P, Scarpa N, Koratzanis G, Thomopoulos G, Giamarellou H: Procalcitonin: a marker to clearly differentiate systemic inflammatory response syndrome and sepsis in the critically ill patient? Intensive Care Med 2002, 28:1351-1356.

45. Rau BM, Frigerio I, Buchler MW, Wegscheider K, Bassi C, Puolakkainen PA, Beger HG, Schilling MK: Evaluation of procalcitonin for predicting septic multiorgan failure and overall prognosis in secondary peritonitis: a prospective, international multicenter study. Arch Surg 2007, 142:134-142.

46. Ueda S, Nishio K, Minamino N, Kubo A, Akai Y, Kangawa K, Matsuo H, Fujimura Y, Yoshioka A, Masui K, Doi N, Murao Y, Miyamoto S: Increased plasma levels of adrenomedullin in patients with systemic inflammatory response syndrome. Am J Respir Crit Care Med 1999, 160:132-136.

47. Giamarellos-Bourboulis EJ, Tsangaris I, Kanni T, Mouktaroudi M, Pantelidou I, Adamis G, Atmatzidis S, Chrisofos M, Evangelopoulou V, Frantzeskaki F, Giannopoulos P, Giannikopoulos G, Gialvalis D, Gourgoulis GM, Kotzampassi K, Katsifa K, Kofinas G, Kontopidou F, Koratzanis G, Koulouras V, Koutsikou A, Koupetori M, Kritselis I, Leonidou L, Mega A, Mylona V, Nikolaou H, Orfanos S, Panagopoulos P, Paramythiotou E, et al: Procalcitonin as an early indicator of outcome in sepsis: a prospective observational study. J Hosp Infect 2011, 77:58-63.

doi:10.1186/cc13064

Cite this article as: Rey et al:: Pro-adrenomedullin, pro-endothelin-1, procalcitonin, C-reactive protein and mortality risk in critically ill children: a prospective study. Critical Care 2013 17:R240.

\section{Submit your next manuscript to BioMed Central and take full advantage of:}

- Convenient online submission

- Thorough peer review

- No space constraints or color figure charges

- Immediate publication on acceptance

- Inclusion in PubMed, CAS, Scopus and Google Scholar

- Research which is freely available for redistribution 